\title{
Intrinsic motivation and motives for Facebook use - a formative measurement approach
}

\author{
Costin Pribeanu \\ Academy of Romanian Scientists \\ Str. Ilfov No.3, Bucharest, Romania \\ costin.pribeanulaosr.ro
}

DOI: $10.37789 /$ rochi.2020.1.1.8

\begin{abstract}
For over a decade, Facebook is part of the everyday life of university students. Its growing popularity stimulated the research aiming to understand the motivations that are driving people to join and use social networking websites. To answer this research question various approaches have been taken: technology acceptance model (TAM), uses and gratification theory, the theory of consumption values, and multidimensional models. The objective of this paper is to analyze the relationship between the intrinsic motivation of using Facebook and the motives for its use. Intrinsic motivation for using Facebook has been conceptualized as perceived enjoyment. The motives for Facebook use have been conceptualized as a formatively-measured construct that impacts two drivers of the intention of use: the perceived enjoyment and the perceived ease of use. The results show that four motives for using Facebook are predicting Facebook's perceived enjoyment: keeping in touch with known people, entertainment, finding useful information and resources, and socialization.
\end{abstract}

\section{Keywords}

Motives for Facebook use, hedonic technologies, MIMIC models, perceived enjoyment, perceived ease of use, formative measurement.

\section{ACM Classification}

D.2.2: Design tools and techniques. H5.2 User interfaces.

\section{INTRODUCTION}

The growing popularity of Facebook among university students stimulated the research in the usage of social networking websites and raised a plethora of research questions that refer to: motives for Facebook use, usage characteristics (frequency and time spent daily, number of Facebook friends), Facebook acceptance and continued use, educational usefulness of Facebook, social learning, social influence, and problematic Facebook use.

Understanding the motives for Facebook use has been an important issue in social media research [1,27]. A review of the extant literature shows various approaches to this research topic, including qualitative and quantitative studies. Several studies used the technology acceptance [32], theory of consumption values [1,32, 33], social action theory $[10]$ or uses and gratifications theory $[10,21]$ to conceptualize the variables of interest then tested the models and analyzed the results by using linear regression, analysis of variance, or structural equation modeling [1, 9, $21,27]$. Several approaches conceptualized the motives for Facebook use as multidimensional models [1, 10, 22].

Although the motives for Facebook use have been extensively researched, few studies are addressing the nature of motivation driving the intention to use.

The objective of this work is to analyze the relationship between the intrinsic motivation of using Facebook and the motives for Facebook use. In the framework of technology acceptance theory, the intrinsic motivation [12] has been conceptualized as perceived enjoyment, defined by Davis et al. [11] as "the extent to which the activity of using a specific system is perceived to be enjoyable in its own rights, aside from any performance consequences resulting from system use".

The motives for Facebook use could be grouped and conceptualized as reflectively measured dimensions of a multidimensional construct $[1,22]$. However, the motives are quite diverse therefore a model addressing several dimensions requires a large number of constructs. A formative measurement approach has the advantage of using a set of indicators corresponding to the main categories of motives.

In this study, the motives for Facebook use have been conceptualized as a formatively measured construct that has an impact on two variables that are driving the intention to use: the perceived ease of use and the perceived enjoyment. In this respect, the study takes the perspective of consumption values theory [30]. This theory borrowed from marketing research has been used by Turel et al. [32] for the acceptance of hedonic artifacts, by Wang et al. [33] for the acceptance of mobile applications, and by Aldawani [1] for the conceptualization of motives for using Facebook.

The formative model has been tested on a sample of 182 Romanian university students.

The rest of this paper is organized as follows. In section 2, related work is discussed with a focus on the motives for using Facebook. The method and results of the empirical study are presented in sections 3 and 4 . The paper ends with a conclusion in section 5 .

\section{RELATED WORK}

\section{Motives for Facebook use}

The motives for using social networking websites, in general, and Facebook, in particular, have been studied from different theoretical perspectives by using both qualitative and quantitative approaches. Ellison et al [15] 
found that keeping in touch with friends and maintaining social relations are important motives for using Facebook by college students.

In the study of Park et al. [27], four primary needs for joining Facebook groups have been identified that vary by gender, hometown, and year in school: self-status seeking, socialization, entertainment and, and information.

Alhabash \& Ma [3] analyzed the motivations of use among college students on four platforms: Facebook, Twitter, Instagram, and Snapchat. They found that the main motives for Facebook use are convenience, entertainment, passing time, medium appeal, and information sharing.

The study of Toker \& Baturay [31] analyzed the factors that influence the use of Facebook for educational purposes. They found that students perceived Facebook as a good tool for communication and collaboration. The most influential factors were the GPA and personal use of Facebook for studying.

A previous study exploring the motives for Facebook use by Romanian university students [25] found that the main reasons are: communication with friends keeping in touch with former high school colleagues, and finding out what is new. Another study [5] analyzed ten motives for Facebook use and found that the most important was to communicate with friends, to find out what happens in university, and to keep in touch with former colleagues.

Iordache \& Pribeanu [22] explored the motives for Facebook use from an educational perspective. They took a multidimensional approach by validating three dimensions: extending social relationships, information and collaboration, and maintaining social relationships. The study found that students are using Facebook mainly for maintaining social relationships.

The study of Cheung et al. [10] took the perspective of social action theory to explain the use of social networks by students. They conceptualized a model by considering the following factors: social influence, social presence, and five key values from uses and gratifications theory (purposive value, social enhancement, self-discovery, interpersonal interconnectivity, and entertainment value).

Ifinedo [21] analyzed the motives for Facebook use from the perspective of uses and gratifications theory. He found that the entertainment value and maintaining interpersonal relationships have the most important influence on the behavioral intention to use.

\section{Hedonic technologies}

The theory of consumption values states that consumer choice is a function of multiple consumption values that are independent and make differential contributions in different choice situations [30]. They identified five key values: functional, conditional, social, emotional, and epistemic. According to the authors, the theory may be used to predict, describe, and explain the consumer's behavior.

Hirschman \& Holbrook [19] defined the hedonic consumption in terms of "consumers' multisensory images, fantasies, and emotional arousal in using a product". In their review of pleasure principles, Alba \& Williams [2] distinguished pleasure in the product (aesthetics, design, having vs. doing) and pleasure from person-product interaction (from expectations and engagement).

Hassenzahl [17] analyzed the hedonic quality as different from the ergonomic quality in the context of humancomputer interaction. He distinguished between pragmatic (utility, usability) and hedonic (identification, stimulation, and evocation) attributes of a product.

Heijden [18] analyzed the differences in technology acceptance models for utilitarian and hedonic systems. As he pointed out, "the value of a hedonic system is a function of the degree to which the user experiences fun when using the system".

Turel et al. [32] analyzed the acceptance of hedonic technologies from the perspective of consumption values theory. They conceptualized the overall hedonic value as a third-order factor model having on the second level four key values: appeal value, social value, playfulness value, and value for money.

Based on a literature review, Aldawani [1] identified four categories of motives for using Facebook (termed as major facets of Facebook gravitation): social, functional, emotional, and, epistemic. Then, based on principal component analysis, he identified eight factors related to the motives for using Facebook: connecting (creating, developing, and maintaining relationships), sharing content, relaxing, branding, organizing (meetings and events), monitoring (friends, celebrities, colleagues), expressing oneself, and learning. The multidimensional approach resulted in a 34-item evaluation instrument. The study of Aldawani is rooted in the consumption values theory applied to the analysis of hedonic technologies.

Wang et al. [33] used the theory of consumption values to analyze the use of mobile applications. In their model, the intention to use is driven by four key values: functional, social, emotional, and epistemic. The results showed that emotional and epistemic values had the strongest influence.

Yang and Lin [34] investigated the motives that influence the stickiness to Facebook from the perspective of a valuebased theory. Their model includes a moderating variable (trust in Facebook) and three values: social value, epistemic value, and hedonic value. The results showed that the hedonic value is positively influencing the stickiness for Facebook. A group analysis showed that in a high-trust group social and hedonic values have a significant impact while in a low-trust group epistemic and hedonic values are significant predictors of the stickiness to Facebook.

\section{Formative measurement models}

In information systems research, a distinction is made between two types of model: measurement model and structural model. The former describes the causal relationships between a latent variable (construct) and its measures (indicators, items, observed variables) while the latter describes the causal relationships between latent variables. According to Anderson and Gerbing [4], before estimating and assigning semantics to the structural model the measurement model has to be correctly specified.

An important issue is the correct specification of the measurement model $[4,6,23]$. 
Following the direction of causal relationships, there are two types of measurement model: reflective and formative (see Figure 1), having distinct characteristics. In the reflective measurement model, the causal direction is from the latent variable to indicators so a change in the latent variable is reflected in simultaneous changes in all indicators. Indicators should be positively correlated and the measurement model should have convergent validity [6].

In formative measurement, the causal direction is from indicators to construct. Indicators are not interchangeable since each is capturing a distinct cause. There are no assumptions on unidimensionality or correlations between indicators. Indicators don't have an error term and items are intercorrelated $[7,8,13,14]$.

a) Reflective model

b) Formative model
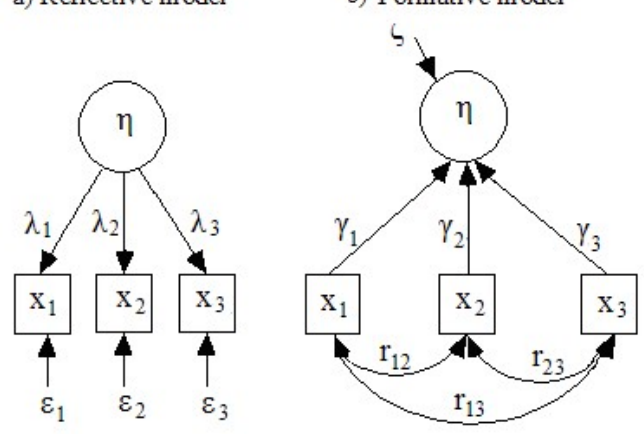

Figure 1. Reflective and formative measurement models

A formative measurement model taken in isolation is under-identified and cannot be estimated. Most authors recommend achieving identification based on the specification of effects (outcomes) on at least two unrelated variables that are reflectively measured. The effect variables could be two reflective indicators (MIMIC model), two reflective constructs, or a reflective construct and a reflective indicator.

\section{METHOD}

\section{Research model and measures}

The motives for using Facebook (FBU) are influencing two variables: the perceived ease of use (PEU) and the perceived usefulness (PU). The research model is presented in Figure 1.

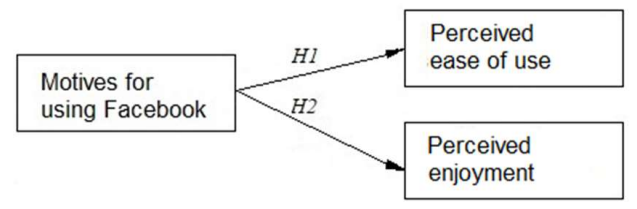

Figure 1. The research model

The following two hypotheses are tested in this study:

[H1] The motives for using Facebook have a positive influence on the perceived ease of use (FBU $\rightarrow$ PEU).

[H2] The motives for using Facebook have a positive influence on perceived enjoyment (FBU $\rightarrow \mathrm{PE})$.
In this research, six categories of motives have been considered: meeting new people, keeping in contact with known people, finding information and resources, socialization, collaboration, and entertainment. The construct "Motives for using Facebook" (FBU) has been conceptualized as a formatively measured construct, having six indicators.

The choice of indicators is based on the results of previous studies [5, 22, 25].

The research model is operationalized as a MIMIC model [24]. MIMIC model is the simplest formative model having multiple indicators (reflectively measured) and multiple causes (formatively measured) of a single latent variable. The variables used in this study are presented in Table 1.

Table 1. Variables

\begin{tabular}{|l|l|}
\hline FBU1 & I use Facebook to get in touch with new people \\
\hline FBU2 & I use Facebook to keep in touch with people I know \\
\hline FBU3 & I use Facebook to find information and resources \\
\hline FBU4 & I use Facebook for socialization purposes \\
\hline FBU5 & I use Facebook for collaboration purposes \\
\hline FBU6 & I use Facebook for entertainment purposes \\
\hline PEU & Facebook is easy to use \\
\hline PE & I like to use Facebook \\
\hline
\end{tabular}

Additionally, two regression models have been tested, in order to analyze the effect of formative indicators on each outcome variable.

\section{Validation criteria}

The following criteria have been used to assess the validity of the model: coverage of the domain of content, correct sign and significance of $\gamma$-coefficients, significant influence on the outcome variables ( $\lambda$-coefficients), and an acceptable fit of the model with the data $[8,14])$.

Based on the recommendations from the literature [16, 20, 29], the following goodness-of-fit measures were used: chisquare $\left(\chi^{2}\right)$, normed chi-square $\left(\chi^{2} / \mathrm{df}\right)$, comparative fit index (CFI), goodness-of-fit index (GFI), standardized root mean square residual (SRMR), and root mean square error of approximation (RMSEA).

The formative measurement model was analyzed with Lisrel 9.3 for Windows [26], using a covariance matrix as input and maximum likelihood estimation method

\section{EMPIRICAL STUDY \\ Sample and data analysis}

The questionnaire has been administrated in May 2019. A total of 194 students from the University of Building Engineering in Bucharest participated in the study. The students have been asked to answer general questions such as demographics (age, gender), enrollment (university, faculty, year of study), FB usage (size of their FB network, frequency of use, minutes per day), then to evaluate items on a 7-points Likert scale. 
A total of 12 questionnaires have been eliminated for incomplete data so the working sample has 182 observations (127 male and 55 female). The age of participants ranges between 18 and 34 years $(M=20.36$, $\mathrm{SD}=2.00)$.

\section{Model estimation results}

The model estimation results are presented in Figure 3

The goodness of fit indices (GOF) indicate a very good level of fit of the proposed model with the data: $\chi^{2}=11.76$, $\mathrm{DF}=5, \mathrm{p}=0.038, \chi^{2} \mathrm{DF}=2.352, \mathrm{CFI}=0.976, \mathrm{GFI}=0.985$, $\mathrm{SRMR}=0.034, \mathrm{RMSEA}=0.086$.

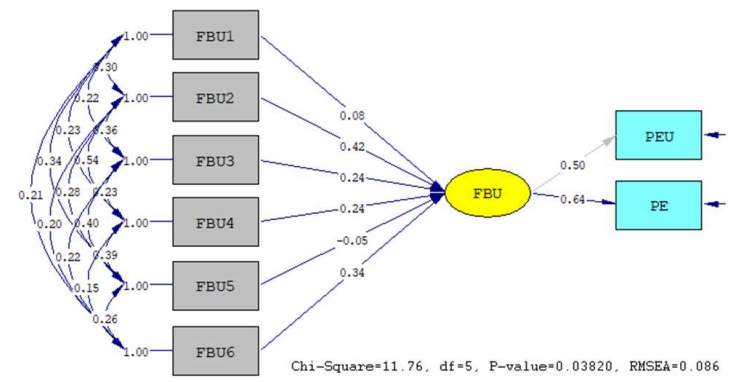

Figure 3. Model estimation results

The descriptive statistics, the influence of the focal construct on the outcomes $(\lambda)$, and $\gamma$-coefficients are presented in Table 2. With one exception (FBU1), the observed scores are over the neutral value of 4.00 . The indicators FBU2, FBU4, and FBU6 have the largest mean values. The influence of FBU on PEU $(\beta=0.50)$ and PE $(\beta=0.64)$ is significant at $p<0.001$ level, which supports the two hypotheses $\mathrm{H} 1$ and $\mathrm{H} 2$. The model explains a $76.3 \%$ variance in the focal construct. The error term (error variance of FBU) is only 0.237 which shows good coverage of the domain of content.

Table 2. Descriptive statistics, loadings( $\lambda)$, and $\gamma$-coefficients

\begin{tabular}{|l|c|c|c|c|c|}
\hline Item & $\mathrm{M}$ & $\mathrm{SD}$ & $\lambda$ & $\gamma$ & Sig. \\
\hline FBU1 & 3.54 & 1.60 & & 0.08 & 0.850 \\
\hline FBU2 & 5.69 & 1.55 & & 0.42 & 0.001 \\
\hline FBU3 & 4.22 & 1.75 & & 0.24 & 0.000 \\
\hline FBU4 & 5.18 & 1.66 & & 0.24 & 0.009 \\
\hline FBU5 & 4.17 & 1.76 & & -0.05 & 0.034 \\
\hline FBU6 & 5.13 & 1.73 & & 0.34 & 0.005 \\
\hline PEU & 6.10 & 1.44 & 0.50 & & 0.000 \\
\hline PE & 4.31 & 1.66 & 0.64 & & 0.000 \\
\hline
\end{tabular}

One indicator has a negative $\gamma$-coefficient (FBU5) and another indicator has nonsignificant $\gamma$-coefficient (FBU1). The formative indicators having the largest $\gamma$-coefficients are FBU2 $(\gamma=0.42, p=0.000)$ and FBU6 $(\gamma=0.34$, $\mathrm{p}=0.000$ ). The other two indicators, FBU3 and FBU4 are significant at $\mathrm{p}<0.05$ level. The correlations between indicators are not too high, bellow the recommended threshold value [14].

The incorrect sign and the lack of significance of FBU1 and
FBU5 suggest that these are not valid measures of the focal construct $[8,14]$ and therefore might be eliminated. The results of testing the revised model are presented in Figure 4.

All four indicators are significant. The largest contribution to the focal construct is given by FBU2 $(\gamma=0.44, p=0.000)$ which shows that keeping in touch with known people has been perceived as the most important motif. Next indicators in the order of importance are FBU6 $(\gamma=0.34, \mathrm{p}=0.000)$, FBU3 $(\gamma=0.24, p=0.011)$, and FBU4 $(\gamma=0.23, p=0.021)$.

Overall, the model explains $75.9 \%$ variance in the motives for using Facebook, $40.7 \%$ in the perceived enjoyment, and $24.9 \%$ in the perceived ease of use.

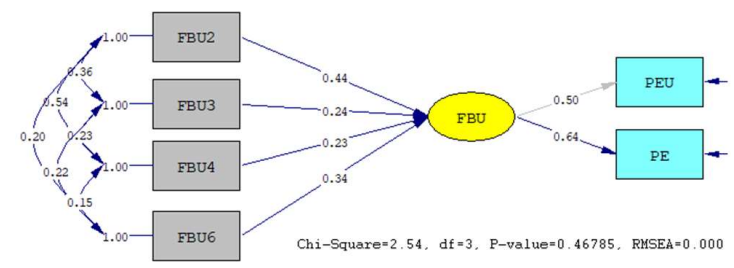

Figure 4. Revised model estimation results

The GOF indices of the revised model are also indicating an excellent fit of the model with the data: $\chi^{2}=2.54, \mathrm{DF}=3$, $\mathrm{p}=0.468, \chi^{2} / \mathrm{DF}=0.836, \mathrm{CFI}=1.000, \mathrm{GFI}=0.995, \mathrm{SRMR}=$ 0.018 , RMSEA $=0.000$.

\section{Regression analysis}

In order to extend the analysis, two regression models have been tested having the perceived enjoyment (PE) and perceived ease of use (PEU) as dependent variables and the six FBU indicators as predictors (independent variables). The results are presented in Table 3 and Table 4.

Table 3. Regression analysis results for PE

\begin{tabular}{|l|r|r|r|r|}
\hline PU & $\beta$ & Error & t-Stat & $p$-value \\
\hline Intercept & -0.04 & 0.49 & -0.08 & 0.937 \\
\hline FBU1 & 0.11 & 0.07 & 1.52 & 0.131 \\
\hline FBU2 & 0.23 & 0.08 & 2.70 & 0.008 \\
\hline FBU3 & 0.14 & 0.07 & 2.00 & 0.047 \\
\hline FBU4 & 0.14 & 0.08 & 1.79 & 0.075 \\
\hline FBU5 & 0.06 & 0.07 & 0.81 & 0.420 \\
\hline FBU6 & 0.22 & 0.06 & 3.52 & 0.001 \\
\hline
\end{tabular}

For PE, the multiple correlation $(\mathrm{R}=57.10)$ is significantly different from $0, \mathrm{~F}(6,181)=14.11, \mathrm{p}=0.000$, with adjusted $\mathrm{R}^{2}=32.61 \%$. The largest influence on PE have FBU2 $(\beta=0.22, p=0.008)$ and FBU6 $(\beta=0.22, p=0.001)$. The regression explains a $30.3 \%$ variance in the perceived enjoyment.

Table 4. Regression analysis results for PEU

\begin{tabular}{|l|r|r|r|r|}
\hline PEU & $\beta$ & Error & t-Stat & p-value \\
\hline Intercept & 3.38 & 0.455 & 7.44 & 0.000 \\
\hline FBU1 & -0.03 & 0.07 & -0.48 & 0.634 \\
\hline
\end{tabular}




\begin{tabular}{l|r|r|r|r|}
\hline FBU2 & 0.29 & 0.08 & 3.61 & 0.000 \\
\hline FBU3 & 0.12 & 0.06 & 1.88 & 0.062 \\
\hline FBU4 & 0.13 & 0.07 & 1.76 & 0.081 \\
\hline FBU5 & -0.14 & 0.07 & -2.13 & 0.035 \\
\hline FBU6 & 0.12 & 0.06 & 2.10 & 0.037 \\
\hline
\end{tabular}

For PEU (Table 4), the multiple correlation is $\mathrm{R}=46.98, \mathrm{~F}$ $(6,181)=8.26, p=0000$, with adjusted $\mathrm{R}^{2}=22.07 \%$. The largest influence has FBU2 $(\beta=0.28, p=0.000)$, then FBU4 $(\beta=0.13, p=0.081)$, and FBU3 $(\beta=0.12, p=0.081)$. Two coefficients (FBU3 and FBU4) are only marginally significant.

The regression explains $19.40 \%$ variance in the perceived ease of use.

\section{Discussion}

The results of this study show that the main reasons why university students Facebook are: keeping in touch with people they know (maintaining social relationships), finding useful information and resources, socialization, and entertainment.

The results are confirming previous findings [22, 25] and are congruent with the results of many studies as regards the social and hedonic value of Facebook [9, 15, 21, 27].

The model explains a $40.7 \%$ variance in the perceived enjoyment. This is not surprising, given the hedonic nature of Facebook [27]. As the results of this study show, three out of four significant motivators for using Facebook have social value (keeping in touch with known people and socialization) and hedonic value (entertainment). As many authors pointed out [10, 15, 34], social activities on Facebook are exciting thus enhancing its perceived hedonic value. Also, for specific social groups (university students, first-year students) socialization itself is enhancing the hedonic value $[19,35]$.

The model estimation results as well as the regression results confirm that two indicators are not suitable. The results are pretty similar as regards the influence of motivators on the two outcome indicators. On the other hand, some differences exist that are explained by the nature of the model.

The regression analyses highlight the particulat relevance of indicators for the outcomes variables. In this respect, FBU2 (keeping in touch with known people) is more relevant for the perceived ease of use than for the perceived usefulness. This suggests that the tasks of keeping in touch with known people are perceived as requiring more effort. On the other hand, the influence of two indicators (FBU3 and FBU4) on the perceived ease of use is only marginally significant.

This work contributes to a deeper understanding of the motives for Facebook use and how these motives are mirrored in the perceived enjoyment and perceived ease of use. There is no quantitative study up to now addressing these research questions from a formative measurement perspective. The main advantage of this approach is an instrument having a small set of indicators.
Second, it shows the advantage of using a mix of methods. The regression analyses enable a better explanation of the formative model estimation results and validation of the formative indicators.

There are several limitations of this exploratory study. First of all, the formative measurement has its own limitations related to model identification and validation. The number of formative indicators is small and two indicators have been eliminated. Future work should enlarge the set of motives for Facebook use.

As many authors pointed out [21, 27, 33], the motives for Facebook use depend on a diversity of factors. Therefore, the conclusions of this study using a sample of college students should not be generalized to other populations.

\section{CONCLUSION AND FUTURE WORK}

This study contributes to a better understanding of the intrinsic motivation for using Facebook by taking a formative measurement approach. The results show that perceived enjoyment is predicted by four main motives for Facebook use: keeping in touch with known people, finding useful information \& resources, socialization, and entertainment.

Although the results are validating a small set of four indicators, representing four categories of motives, the model is explaining $76 \%$ of the variance in the latent variable, which shows good coverage of the formative indicators and suggests a promising starting point for future studies.

\section{REFERENCES}

1. Aladwani, A. M. (2014). Gravitating towards Facebook (GoToFB): What it is? and How can it be measured?. Computers in Human Behavior, 33, 270278. http://dx.doi.org/10.1016/j.chb.2014.01.005

2. Alba, J. W., \& Williams, E. F. (2013). Pleasure principles: A review of research on hedonic consumption. Journal of consumer psychology, 23(1), 2-18. https://doi.org/10.1016/j.jcps.2012.07.003

3. Alhabash, S., \& Ma, M. (2017). A tale of four platforms: Motivations and uses of Facebook, Twitter, Instagram, and Snapchat among college students?. Social Media + Society, 3(1), 2056305117691544. https://doi.org/10.1177/2056305117691544

4. Anderson, J.C. \& Gerbing, D.W. (1988) Structural Equation Modeling in Practice: A Review and Recommended Two-Step Approach. Psychological Bulletin, 103(3), 411-423.

5. Balog, A., Pribeanu, C. Ivan, I. (2015) Motives and characteristics of Facebook use by students from a Romanian university. In: Dardala, M., Rebedea, T.E. (Eds.) Proceedings of RoCHI 2015, Bucharest, 24-25 September, 137-140.

6. Bagozzi, R. P. (2011). Measurement and meaning in information systems and organizational research: methodological and philosophical foundations. MIS Quarterly, 35(2), 261-292.

7. Bollen, K. A., \& Diamantopoulos, A. (2017). In defense of causal-formative indicators: A minority report. Psychological Methods, 22(3), 581. DOI: 10.1037/met0000056 
8. Boolen, K. (2011) Evaluating effect, composite and causal indicators in structural equation models. MIS Quarterly, 35(2), 359-372.

9. Chang, C. C., Hung, S. W., Cheng, M. J., \& Wu, C. Y. (2014). Exploring the intention to continue using social networking sites: The case of Facebook. Technological Forecasting and Social Change, 95, 4856. https://doi.org/10.1016/j.techfore.2014.03.012

10. Cheung, K., Chiu, P.-Y., Lee, M. (2014) Online social networks: Why do students use Facebook. Computers in Human Behavior, 27(4), 1337-1343. https://doi.org/10.1016/j.chb.2010.07.028

11. Davis, F.D., Bagozzi, R.P., Warshaw, P.R. (1992). Extrinsic and intrinsic motivation to use computers in the workplace. Journal of Applied Social Psychology, 22 (14), 1111-1132.

12. Deci, E. L., Vallerand, R. J., Pelletier, L. G., \& Ryan, R. M. (1991). Motivation and education: The selfdetermination perspective. Educational psychologist, 26(3-4), 325-346.

13. Diamantopoulos, A., \&Winklhofer, H. (2001). Index construction with formative indicators: an alternative to scale development. Journal of Marketing Research, 38(2), 269-277.

14. Diamantopoulos A. (2011) Incorporating formative measures into covariance-based structural equation models. MIS Quarterly, 35 (2). 335-358.

15. Ellison, N.B., Steinfield, C., Lampe, C. (2007). The benefits of Facebook "Friends:" Social capital and college students' use of online social network sites, Journal of Computer-Mediated Communication, 12, 1143-1168

16. Hair, J.F., Black, W.C., Babin, B.J., Anderson, R.E., Tatham, R.L. (2006). Multivariate Data Analysis. 6th ed., Prentice-Hall.

17. Hassenzahl, M. The Thing and I: Understanding the Relationship Between User and Product. In Blythe, M., Overbeeke, K., Monk, A., and Wright, P. (Eds.). Funology: From Usability to Enjoyment. Kluwer Academic Publishers, 2005, 31-42

18. Heijden, H. van der (2004). User acceptance of hedonic information systems. MIS Quarterly, 28 (4), 695-704.

19. Hirschman, E. and Holbrook, M.B. (1982), "Hedonic consumption: emerging concepts, methods and propositions", Journal of Marketing, Vol. 46 No. 3, pp. 92-101

20. Hu, L. T., \& Bentler, P. M. (1998). Fit indices in covariance structure modeling: Sensitivity to under parameterized model misspecification. Psychological methods, 3(4), 424.

21. Ifinedo, P. (2016). Applying uses and gratifications theory and social influence processes to understand students' pervasive adoption of social networking sites: Perspectives from the Americas. International Journal of Information Management, 36(2), 192-206. http://dx.doi.org/10.1016/j.ijinfomgt.2015.11.007

22. Iordache, D. D., \& Pribeanu, C. (2016). Exploring the motives of using Facebook - a multidimensional approach. Revista Romana de Interactiune OmCalculator, 9(1), 19-34.

23. Jarvis, C.B., Mackezie, S., Podsakoff, M. (2003) A critical review of construct indicators and measurement models misspecification in marketing and consumer research. Journal of Consumer Research 30, 199-218.

24. Jöreskog, K. G., \& Goldberger, A. S. (1975). Estimation of a model with multiple indicators and multiple causes of a single latent variable. Journal of the American Statistical Association, 70(351a), 631639.

25. Manea, V.I., Gorghiu, G., Iordache, D.D. (2015) The educational potential of Facebook use by students in two Romanian universities. Revista Romana de Interactiune Om-Calculator 8(3), 195-208.

26. Mels, G. (2006). LISREL for Windows: Getting Started Guide. Lincolnwood: Scientific Software International, Inc.

27. Park, N., Kee, K. F., Valenzuela, S. (2009). Being immersed in social networking environment: Facebook groups, uses and gratifications, and social outcomes. CyberPsychology \& Behavior, 12(6), 729733.

28. Rosen, P., Sherman, P. (2006) Hedonic information systems: Acceptance of social networking websites. Proceedings of AMCIS 2006, Acapulco, 4-6 August, 1218-1223.

29. Schermelleh-Engel, K., Moosbrugger, H., \& Müller, H. (2003). Evaluating the fit of structural equation models: Tests of significance and descriptive goodness-of-fit measures. Methods of psychological research online, 8(2), 23-74

30. Sheth, J. N., Newman, B. I., \& Gross, B. L. (1991). Why we buy what we buy: A theory of consumption values. Journal of Business Research, 22(2), 159-170.

31. Toker, S., \& Baturay, M. H. (2019). What foresees college students' tendency to use Facebook for diverse educational purposes?. International Journal of Educational Technology in Higher Education, 16(1), 9. https://doi.org/10.1186/s41239-019-0139-0

32. Turel, O., Serenko, A., \& Bontis, N. (2010). User acceptance of hedonic digital artifacts: A theory of consumption values perspective. Information \& Management, 47(1), 53-59.

33. Wang, H. Y., Liao, C., \& Yang, L. H. (2013). What affects mobile application use? The roles of consumption values. International Journal of Marketing Studies, 5(2), 11-22, DOI:10.5539/ijms.v5n2p11

34. Yang, H. L., \& Lin, C. L. (2014). Why do people stick to Facebook web site? A value theory-based view. Information Technology \& People, 27(1), 2137. http://dx.doi.org/10.1108/ITP-11-2012-0130.

35. Yang, C. C., \& Brown, B. B. (2013). Motives for using Facebook, patterns of Facebook activities, and late adolescents' social adjustment to college. Journal of youth and adolescence, 42(3), 403-416. DOI 10.1007/s10964-012-9836-x. 